\title{
ESSENTIAL FORMULAE FOR ELECTRONIC AND ELECTRICAL ENGINEERS
}

Noel M. Morris 
(c) Noel M. Morris 1974

All rights reserved. No part of this publication may be reproduced or transmitted, in any form or by any means,

without permission

First published 1974

Reprinted 1977, 1981

Published by

THE MACMILLAN PRESS LTD

London and Basingstoke

Companies and representatives

throughout the world

ISBN 978-0-333-16866-0

ISBN 978-1-349-02285-4 (eBook) DOI 10.1007/978-1-349-02285-4

Typeset in Great Britain by

PREFACE LIMITED

Salisbury, Wiltshire

The paperback edition of this book is sold subject to the condition that it shall not, by way of trade or otherwise, be lent, re-sold, hired out, or otherwise circulated without the publisher's prior consent in any form of binding or cover other than that

in which it is published and without a similar condition including this condition being imposed on the subsequent purchaser 


\section{CONTENTS}

Preface

Resistor colour code

Preferred values for resistors and capacitors

Multiples and submultiples of 10

Greek alphabet

Dimensions and dimensional analysis

Basic and supplementary SI units

Derived units in the MLTQ system

Mechanics

Equations of motion

Torque

Force, work, energy and power

Electrostatics

Data relating to the electron, the proton, the neutron, and free space

Electric flux density

Electric field strength

Absolute permittivity

Force between two charges

Energy stored in a cubic metre of a dielectric

Capacitance

Energy stored in a capacitor

Capacitance of a parallel-plate capacitor with $n$ plates

Capacitors in parallel

Capacitors in series

Ratio of field strengths in two dielectric in series

Capacitance of concentric spheres

Capacitance of an isolated sphere

Capacitance per metre of two concentric cylinders

Capacitance per metre of two parallel bare wires

Capacitance per metre of a single conductor to earth

Capacitance per metre of line 1 of an isolated three-phase line

Force on an isolated electron in an electric field

Final velocity of a free electron in an electric field

Transverse deflection of an electron in an electrostatic C.R.T.

Force of attraction between charged plates

\section{Electromagnetism}

Magnetic constant of free space

Reluctance

Magnetomotive force

Magnetic flux

Magnetic flux in a composite circuit
Leakage factor

Magnetic flux density

Magnetic field intensity

Absolute permeability

Force on a current-carrying conductor in a magnetic field

Torque on a coil in a magnetic field

Force on an isolated electron moving at velocity $u$ in a magnetic field

Deflection of an electron in a magnetic field

E.M.F. generated in a conductor

Self induced e.m.f.

Magnetising force in a long solenoid

Magnetising force at distance $x$ from the centre of a straight wire

Flux density in air at distance $x$ from the centre of a straight wire

Energy stored per cubic metre in a magnetic field

Force between two magnetised surfaces

Force per metre between two parallel conductors

Inductance

Inductance of a homogeneous magnetic circuit Inductance per metre of two parallel wires Inductance of a concentric cable

Magnetic energy stored in an inductor

E.M.F. induced in an inductance

Inductance per metre of coils in series, not magnetically coupled

Inductance of coils in parallel, not magnetically coupled

Mutual inductance

Coupling coefficient

Inductance of two coils in series which are magnetically coupled

Coupled circuits with alternating e.m.f. $E_{1}$ in the primary and $E_{2}$ in the secondary

Hysteresis loss

Electric circuits

\section{Resistance}

Resistors in series

Resistors in parallel

Variation of resistance with temperature

Voltage

Current

Power

Energy

Division of current in parallel resistors $R_{1}$ and $R_{2}$

Division of voltage between series resistors $R_{1}$ and $R_{2}$

Circuit theorems

Kirchhoff's laws 
Norton's theorem

Millman's theorem

Star-mesh transformation

Delta-star transformation

Maximum power transfer theorem

Superposition theorem

Reciprocity theorem

Compensation theorem

Complex numbers

Rectangular form

Polar form

Exponential form

Single phase a.c. circuits

Frequency

Angular frequency

Instantaneous e.m.f.

Average e.m.f.

R.M.S. value

Average value of a rectified sine wave

Sine wave: r.m.s. value, form factor, peak factor

Reactance: inductive, capacitive

Series circuit impedance

Impedances in series

Current in a series circuit

Series circuit resonance

$Q$-factor of a series circuit

Conductance

Susceptance

Admittance

Current in a parallel circuit

Parallel resonance

$Q$-factor of a parallel tuned circuit

Impedance of a tuned circuit near resonance

Power

Power factor

Current

Volt-amperes

Complex waves: r.m.s. value; power; reactance

Three phase a.c. circuits

Voltage relationships: star, delta

Power in a balanced load

Two wattmeter method of measuring power

Operator $a$ (or $h$ )

Symmetrical components

Transients

First-order circuits, step function response

Second-order circuits, step function response

\section{Rectification}

Single-phase half-wave controlled

Ripple

Fourier expressions

Simple $R-C$ ripple filter; ripple voltage, load voltage

Rectifier circuit data; single phase; three phase
Bridge measuring circuits

Kirchhoff

De Sauty 11

Schering 11

Owen 11

Wien 11

Instruments

Moving-coil instruments $\quad 11$

Ballistic galvanometer $\quad 12$

Fluxmeter $\quad 12$

Induction instruments $\quad 12$

Logic

Basic theorems 12

De Morgan's theorem 12

Laws: commutative; associative; distributive $\quad 12$

Logic gates

OR, AND, NOT, NOR, NAND functions 13

Truth tables for two-input gates 13

Values of $2^{ \pm N}$

Equivalent circuits and four-terminal network equations

$h$-parameters 13

$y$-parameters 13

$A B C D$ parameters $\quad 13$

Electronic amplifiers

Relationship between the general $h$ - and $y$-parameters

Relationship between common-emitter, common-base and common-collector $h$-parameters

Common-emitter amplifier equations

Common-base amplifier equations

Common-collector amplifier equations (emitter follower)

Common-source amplifier equations

Feedback amplifiers

Effects of feedback

Voltage gain of a series voltage feedback amplifier

Summing amplifier

Integrator

Effect of feedback on bandwidth

Conditions for instability in a closed-loop amplifier

Oscillators

Conditions for maintenance of oscillations

Oscillators: Colpitts; Hartley; Wien bridge; $\mathrm{R}-\mathrm{C}$ ladder 
Symmetrical astable multivibrator

Monostable multivibrator

Control systems

Equation of motion of a second-order r.p.c. servosystem

Response to a step input

Response to a ramp input $\left(\theta_{\mathrm{i}}=\omega t\right)$

Velocity lag in an underdamped second-order system

Effect of load torque on a simple system

D.C. machines

Basic relationships

Per-unit efficiency

Transformers

E.M.F. equation

Turns ratio

Equivalent resistance referred to the primary

Equivalent leakage reactance referred to the primary

Voltage regulation

Efficiency

Synchronous machines

Frequency

Distribution factor or breadth factor

Coil-span factor or pitch factor

E.M.F. per phase

Voltage regulation

Torque per phase

Mechanical power

Induction machines

Speed of rotation of the magnetic field

Per-unit slip

Frequency of rotor current

Rotor e.m.f. per phase

Rotor impedance per phase
Input power 18

Rotor copper loss 18

Rotor output power $\quad 18$

Torque developed 18

Condition for maximum torque $\quad 18$

Starting torque 18

Circle diagram $\quad 18$

The per-unit system $\quad 19$

Power system short circuits

Base values

Modulation

Amplitude modulation $\quad 20$

Phase modulation 20

Frequency modulation $\quad 20$

Transmission lines

Line equations $\quad 20$

Exponential forms of the equations 20

Phase velocity of transmission $\quad 20$

Wavelength $\quad 20$

$\begin{array}{ll}\text { Algebra } & 20\end{array}$

Series (including the Fourier series) 21

$\begin{array}{ll}\text { Trigonometry } & 23\end{array}$

Determinants $\quad 24$

Differential calculus $\quad 24$

$\begin{array}{lr}\text { Integral calculus } & 25\end{array}$

Operator D 25

$\begin{array}{lr}\text { Partial fractions } & 25\end{array}$

Laplace transforms $\quad 26$

\section{PREFACE}

The continued growth of electronic and electrical engineering has increased the demands on students to the point where it is practically impossible to memorise all the formulae they need. This book contains the essential formulae in the fields of electronics, electrical engineering, control systems, measurements, logic, telecommunications and mathematics. It will be of great value to students following a wide range of courses including City and Guilds of London Institute courses, science-based Advanced Level General Certificate of Education courses, Ordinary and Higher National Certificates and Diplomas and B.Sc. courses. Established engineers who use formulae in the course of their work will find it a convenient source of reference. The SI system of units is used throughout. 